\title{
Development of tissue inflammation accompanied by NLRP3 inflammasome activation in rabbits infected with Treponema pallidum strain Nichols
}

\author{
Li-Rong Lin ${ }^{1,2+}$, Yao Xiao ${ }^{1,3+}$, Wei Liu ${ }^{1,2+}$, Yu-Yan Chen ${ }^{4}$, Xiao-Zhen Zhu ${ }^{1,2}$, Zheng-Xiang Gao ${ }^{1,2}$, Kun Gao ${ }^{1,2}$, \\ Man-Li Tong ${ }^{1,2}$, Hui-Lin Zhang ${ }^{1,2}$, Shu-Lian Li $i^{5}$, Hui-Ling Lin ${ }^{5}$, Wen-Dong Li $i^{5}$, Xian-Ming Liang ${ }^{1}$, Yong Lin ${ }^{1,2^{*}}$, \\ Li-Li Liu ${ }^{1,2^{*}}$ and Tian-Ci Yang ${ }^{1,2^{*}}$ (D)
}

\begin{abstract}
Background: The inflammasome responses in Treponema pallidum infection have been poorly understood to date. This study aimed to investigate the expression of the nucleotide-binding leucine-rich receptor protein 3 (NLRP3) inflammasome in the development of tissue inflammation in rabbits infected with T. pallidum.

Methods: Forty-five rabbits were randomly assigned to a blank group or an infection group, and the latter was divided into no benzathine penicillin G (BPG) and BPG treatment subgroups. Rabbits in the infection group were injected intradermally with $0.1 \mathrm{~mL}$ of a $10^{7} / \mathrm{mL}$ T. pallidum suspension at 10 marked sites along the back, and the blank group was treated with normal saline. The BPG treatment subgroup received 200,000 U of BPG administered intramuscularly twice, at $14 \mathrm{~d}$ and $21 \mathrm{~d}$ post-infection. The development of lesions was observed, and biopsies of the injection site and various organs, including the kidney, liver, spleen, lung, and testis, were obtained for NLRP3, caspase-1, and interleukin-1 $\beta$ (IL-1 13$)$ mRNA analysis during infection. Blood was also collected for the determination of IL-1 $\beta$ concentration.

Results: Rabbits infected with T. pallidum (both the BPG treatment and no BPG treatment subgroups), exhibited NLRP3 inflammasome activation and IL-1 $\beta$ secretion in cutaneous lesions, showing a trend in elevation to decline; NLRP3 mRNA expression reached a peak at $18 \mathrm{~d}$ in the BPG treatment subgroup and $21 \mathrm{~d}$ in the no BPG treatment subgroup and returned to "normal" levels [vs. the blank group $(P>0.05)$ ] at $42 \mathrm{~d}$ post-infection. The trend was similar to the change in cutaneous lesions in the infected rabbits, which reached a peak at $16 \mathrm{~d}$ in the BPG treatment subgroup and $18 \mathrm{~d}$ in the no BPG treatment subgroup. NLRP3, caspase-1, and IL-1 3 mRNA expression levels were slightly different in different organs. NLRP3 inflammasome activation was also observed in the kidney, liver, lung, spleen and testis. IL-1 $\beta$ expression was observed in the kidney, liver, lung and spleen; however, there was no detectable level of $I L-1 \beta$ in the testes of the infected rabbits.
\end{abstract}

Conclusions: This study established a clear link between NLRP3 inflammasome activation and the development of tissue inflammation in rabbits infected with T. pallidum. BPG therapy imperceptibly adjusted syphilitic inflammation.

Keywords: Treponema pallidum, Inflammation, NLRP3, II-1ß, Rabbit

\footnotetext{
*Correspondence: mikhail929@163.com; liulili@xmu.edu.cn;

yangtianci@xmu.edu.cn

${ }^{\dagger}$ Equal contributors

'Zhongshan Hospital, Medical College of Xiamen University, Xiamen, Fujian

Province, China

Full list of author information is available at the end of the article
}

(c) The Author(s). 2018 Open Access This article is distributed under the terms of the Creative Commons Attribution 4.0 International License (http://creativecommons.org/licenses/by/4.0/), which permits unrestricted use, distribution, and reproduction in any medium, provided you give appropriate credit to the original author(s) and the source, provide a link to the Creative Commons license, and indicate if changes were made. The Creative Commons Public Domain Dedication waiver (http://creativecommons.org/publicdomain/zero/1.0/) applies to the data made available in this article, unless otherwise stated. 


\section{Background}

Syphilis is a sexually transmitted disease caused by the bacterial spirochete Treponema pallidum [1]. The inflammatory processes induced by $T$. pallidum within infected tissues result in the development of lesions, and lesion resolution has been reported previously [2]. The innate immune system, the first line of host defense of microbial infection, is recognized as the major contributor to the acute inflammation induced by tissue damage or microbial infection [3]. The innate immune system has an imperative function in controlling the initial pathogen invasion and activates various members of the nucleotide-binding leucine-rich receptor (NLR) family in the cytoplasm, resulting in the assembly of an NLR-containing multiprotein complex that recruits and activates caspase-1, leading to interleukin-1 $\beta$ (IL-1 $\beta$ ) production [4].

NLRP3 is the best-characterized member of the NLR family involved in the innate immune system; this system is activated by exogenous and endogenous stimulatory factors, such as bacteria, viruses, fungi, and components of dying cells $[5,6]$, and NLRP3 serves as a platform for the activation of caspase- 1 and the maturation of the proinflammatory cytokine IL-1 $\beta$ to engage in the innate immune response [7]. The role of the NLRP3 inflammasome in pathogenic infections, such as those caused by Pneumococcus [8], Helicobacter pylori [9], Neospora caninum [10], and Mycobacterium tuberculosis [11] has been demonstrated. However, the involvement of NLRP3 in the inflammatory processes of $T$. pallidum infection is poorly understood.

In this study, we investigate the expression of the NLRP3 inflammasome during the development of tissue inflammation associated with syphilis, the activation of the inflammasome and release of IL- $1 \beta$ were estimated during $T$. pallidum infection in a rabbit model.

\section{Methods}

\section{Animal experiments}

The $T$. pallidum Nichols strain was kindly provided by Lorenzo Giacani, Ph.D. (University of Washington, Seattle) and was propagated via intra-testicular serial passage in New Zealand white rabbits to maintain virulence in our laboratory as previously described [12]. Forty-five male New Zealand white rabbits (purchased from the Xiamen University Laboratory Animal Center, weighing approximately three kilograms each) with negative results in both the reactive rapid plasma reagin and T. pallidum particle agglutination tests, were randomly assigned to two groups, a blank group $(n=15)$ and an infection group $(n=30)$. The latter was divided into the no benzathine penicillin G (BPG) treatment subgroup ( $n=15)$ and the BPG treatment subgroup ( $n$ $=15$ ). The animals were housed individually at 16 to
$18{ }^{\circ} \mathrm{C}$ and were fed with antibiotic-free food and water. Rabbits in the infection group were injected intradermally with $0.1 \mathrm{~mL}$ of a $10^{7}$ treponeme $/ \mathrm{mL}$ suspension at 10 marked sites along the back, while rabbits in the blank group were injected with normal saline. The backs of the rabbits were meticulously kept free of fur by daily clipping throughout the experiment. Rabbits in the BPG treatment subgroup received 200,000 U of BPG administered intramuscularly twice, at $14 \mathrm{~d}$ and $21 \mathrm{~d}$ post-infection.

One representative site of each animal was selected separately and biopsied (4-mm punch biopsies obtained under local lidocaine anesthesia) for RNA extraction at $1,4,7,10,14,18,21,28,35$ and $42 \mathrm{~d}$ post-infection. One representative site on each animal was dedicated exclusively for the observation of lesion appearance and development up to $42 \mathrm{~d}$ post-infection; the diameter of the lesion was measured using a vernier caliper. Three animals were randomly selected for euthanasia in the two groups at $7,14,21,28$, and $42 \mathrm{~d}$ post-infection, and the kidney, liver, spleen, lung, and testis organs were then harvested for experimental analysis. Blood was collected at $1,4,7,10,14,18,21,28,35$ and $42 \mathrm{~d}$ postinfection, and serum was isolated and frozen at $-80{ }^{\circ} \mathrm{C}$ until analysis of the IL- $1 \beta$ concentration. All protocols involving animals were approved in advance by the animal experimental ethics committee of the Medical College of Xiamen University.

\section{NLRP3/caspase-1/ IL-1 $\beta$ mRNA expression analysis}

To assess the expression of mRNA, total RNA from lesions/tissues was isolated using the RNeasy Kit (Qiagen Inc., Valencia, CA) and was reverse transcribed using a high-capacity cDNA reverse transcription kit (Takara Inc., Dalian, China). The generated cDNA was amplified using quantitative PCR assays and the SYBR Advantage PCR Premix (Takara Inc., Dalian, China) with the 7500 Real Time PCR System (Applied Biosystems, Carlsbad, USA). The following primer pairs were used: NLRP3, (5'-CCACTTCCCCAGAATCGAGA-3' and 5'-TGGAC GTGAGACAGGAGTTC-3'); Caspase-1, (5'-CAAGTCT CAAGCTTTGCCCG-3' and 5'-TAATGAGGGCAAGA CGGGTG-3'); $I L-1 \beta$, (5'-GGATGACGGCCTGAGAAC TT-3' and 5'-TACGTGCCAGACAACACCAA-3'); and GAPDH, (5'-GCTTCTTCTCGTGCAGTGCA-3' and 5'ATGACCAGCTTCCCGTTCTC -3'). After amplification, $\mathrm{Ct}$ values were normalized to $G A P D H$ as an internal control, and the relative copy number was determined using the standard $2^{-\Delta \Delta \mathrm{Ct}}$ method [13]. A commercial enzyme-linked immunosorbent assay kit (Cloud-Clone Inc., USA) was used to measure the IL-1 $\beta$ levels in the rabbit serum samples according to the manufacturer's instructions. 


\section{Statistical analysis}

The data were expressed as the mean \pm SD. Statistical analyses were performed using the SPSS 13.0 software (SPSS Inc., Chicago, USA). Student's t-test was applied to compare the means between two groups. In cases with more than two groups, a one-way analysis of variance was employed to examine the differences between the groups, and Dunnett's post-comparison test was used to conduct multiple comparisons. A 2-tailed $P$ value of less than 0.05 was accepted as being statistically significant.

\section{Results}

\section{Development of cutaneous lesions in rabbits infected with $T$. pallidum}

In the infected rabbits, cutaneous lesions began to develop at $4 \mathrm{~d}$ post-infection and then reached a peak at $16 \mathrm{~d}$ in the BPG treatment subgroup and at $18 \mathrm{~d}$ in the no BPG treatment subgroup (Fig. 1a, b). In the BPG treatment subgroup, the lesions gradually began to shrink at $16 \mathrm{~d}$ ( $2 \mathrm{~d}$ after the first BPG treatment) and subsequently disappeared at $28 \mathrm{~d}$ post-infection. The cutaneous lesions disappeared at an earlier time point in the BPG treatment subgroup than that in the no BPG treatment subgroup ( $28 \mathrm{~d}$ vs. $42 \mathrm{~d}$ ). The lesions were barely detectable at $35 \mathrm{~d}$ and disappeared at $42 \mathrm{~d}$ in the no BPG treatment subgroup. The cutaneous lesions in the no BPG treatment subgroup were significantly larger than those in the BPG treatment subgroup at 18,21, 24, 28 and $35 \mathrm{~d}$ post-infection (Fig. 1c) $(P<0.05)$. No lesions developed in the blank group (data not shown).

\section{NLRP3 inflammasome activation in the cutaneous lesions of infected rabbits}

In the infected rabbit group, the NLRP3 mRNA levels showed a trend in elevation to decline and reached a peak at $18 \mathrm{~d}$ post-infection in the BPG treatment subgroup and at $21 \mathrm{~d}$ in the no BPG treatment subgroup. In the BPG treatment subgroup, NLRP3 mRNA expression was suppressed at $18 \mathrm{~d}$ post-infection $(4 \mathrm{~d}$ after the first BPG treatment) and returned to "normal" levels [(i.e., not significantly different from the blank group $(P>$ $0.05)$ ] at $42 \mathrm{~d}$ post-infection. Notably, the level of NLRP3 mRNA exhibited a reduction at an earlier time point in the BPG treatment subgroup $(18 \mathrm{~d})$ than that in the no BPG treatment subgroup $(21 \mathrm{~d})$. The expression of NLRP3 mRNA in the no BPG treatment subgroup was significantly higher than that in the BPG treatment subgroup at 21,28 , and $35 \mathrm{~d}$ post-infection $(P<0.05)$ (Fig. 2a). However, the expression of caspase- 1 and $I L-1 \beta$ mRNA showed a "saddle pattern" of change over time post-infection; caspase- 1 expression reached an initial peak at $7 \mathrm{~d}$ and a second peak at $28 \mathrm{~d}$, while $I L-1 \beta$
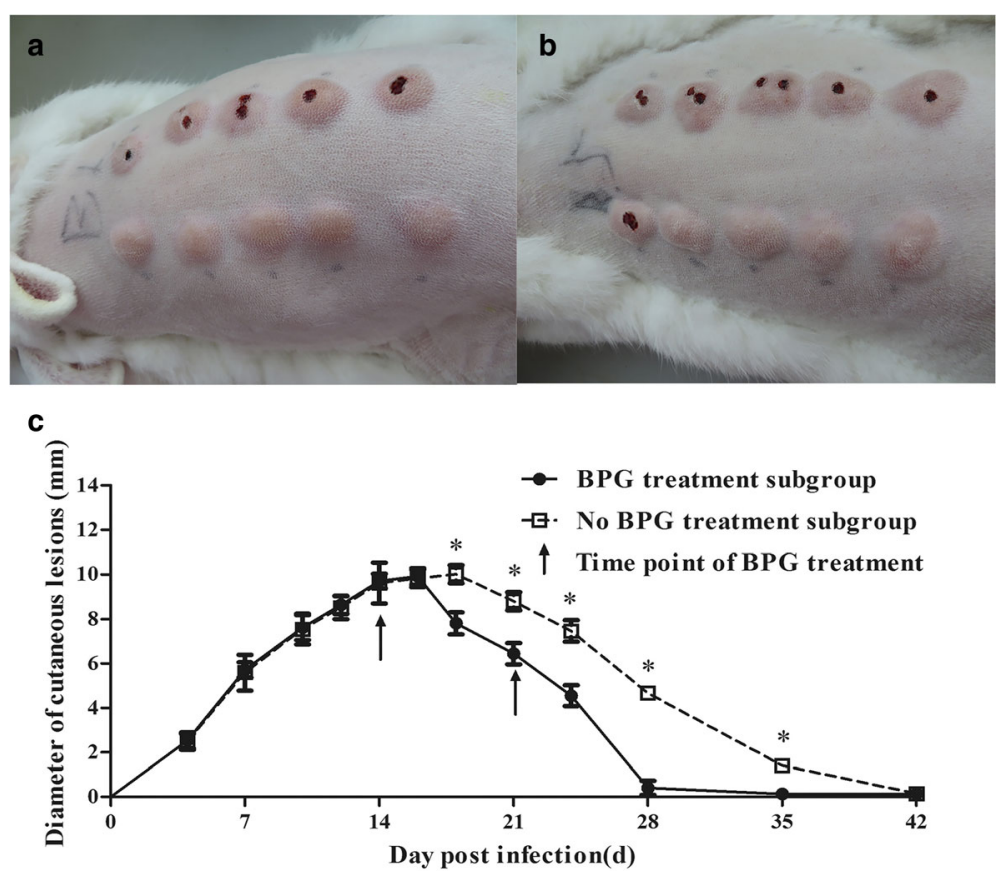

Fig. 1 Dynamics of the cutaneous lesion size in rabbits infected with T. pallidum. a Lesions of one representative rabbit in the BPG treatment subgroup at $16 \mathrm{~d}$. $\mathbf{b}$ Lesions of one representative rabbit in the no BPG treatment subgroup at $18 \mathrm{~d}$. $\mathbf{c}$ Dynamics of the cutaneous lesion size in rabbits infected with $T$. pallidum. The arrow shows the time point of BPG treatment. The results are expressed as the mean \pm SD. Student's $t$-test was applied to compare the means of the diameters between the BPG treatment and no BPG treatment subgroups. ${ }^{*} P<0.05$ 

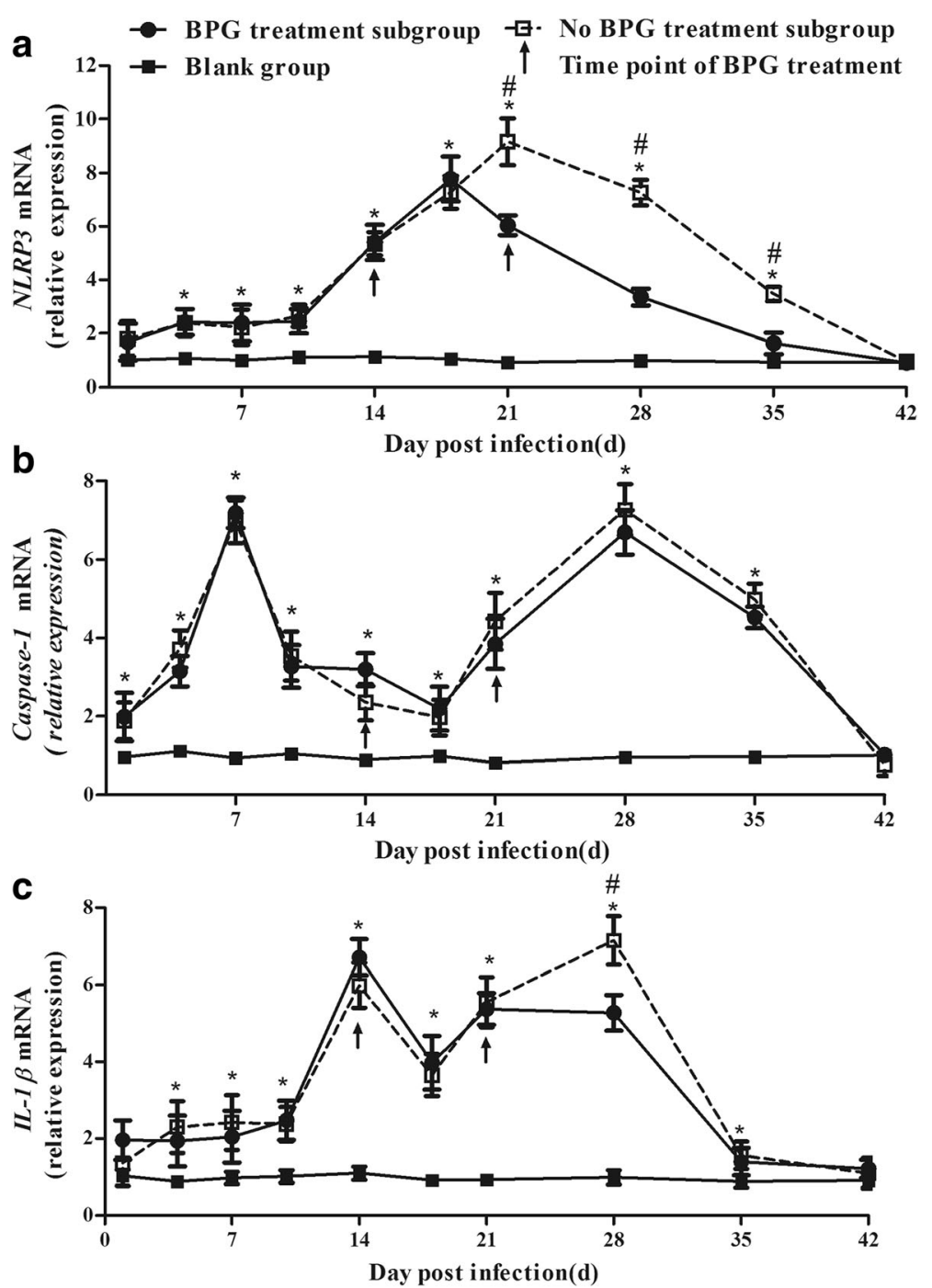

Fig. 2 Dynamics of NLRP3, caspase-1, and IL-1 $\beta$ mRNA expression in cutaneous lesions in rabbits infected with T. pallidum. a Dynamics of NLRP3 mRNA in cutaneous lesions in rabbits infected with T. pallidum. b Dynamics of caspase-1 mRNA in cutaneous lesions in rabbits infected with $T$. pallidum. c Dynamics of IL-1 $\beta$ mRNA in cutaneous lesions in rabbits infected with T. pallidum. The arrow shows the time point of BPG treatment. Values represent the mean \pm SD of triplicate experiments. A one-way analysis of variance was employed to examine the differences in the three groups, and Dunnett's post-comparison test was used to conduct multiple comparisons. ${ }^{*} P<0.05$, the BPG treatment subgroup or no BPG treatment subgroup vs. the blank group. \# $P<0.05$, the BPG treatment subgroup vs. the no BPG treatment subgroup

mRNA reached a first peak at $14 \mathrm{~d}$ and a second peak at $28 \mathrm{~d}$ in both the BPG treatment and no BPG treatment subgroups (Fig. 2b, c). Notably, despite different trends in the expression of NLRP3, caspase-1, and $I L-1 \beta$ mRNAs in cutaneous lesions during infection, at $42 \mathrm{~d}$ post-infection, the expression of all three mRNAs returned to "normal" levels [i.e., were not significantly different from the blank group levels $(P>0.05)]$ in both the BPG treatment and no BPG treatment subgroups. The expression of NLRP3, caspase-1, and $I L-1 \beta$ mRNAs was maintained at a lowel and showed no fluctuations in the blank group during the experimental period (Fig. 2).

\section{IL-1 $\beta$ secretion in rabbits infected with $T$. pallidum}

Except at $1 \mathrm{~d}$ and $42 \mathrm{~d}$ post-infection, the IL- $1 \beta$ concentration in the infection group was significantly higher than that in the blank group, which maintained a low level with no fluctuations. The dynamic tendency of the serum IL- $1 \beta$ concentration in the BPG treatment subgroup was similar to that in the no BPG treatment subgroup, which presented a trend of increasing early and a later decrease (Fig. 3). The serum IL-1 $\beta$ level reached a peak at $18 \mathrm{~d}$ in the BPG treatment subgroup and at $21 \mathrm{~d}$ in the no BPG treatment subgroup, before returning to normal levels [i.e., not significantly different 


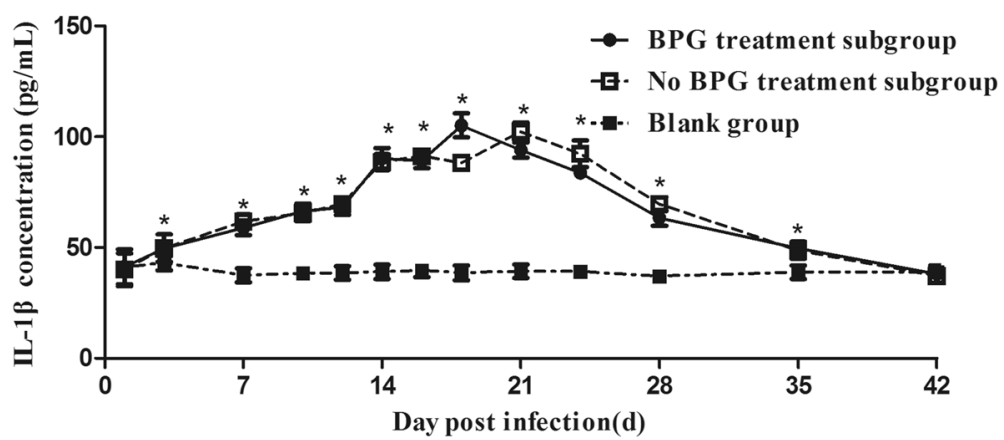

Fig. 3 Dynamics of the IL-1 $\beta$ concentration in rabbits infected with T. pallidum. Values represent the mean \pm SD of triplicate experiments. A one-way analysis of variance was employed to examine the differences between groups, and Dunnett's post-comparison test was used to conduct multiple comparisons. * $P<0.05$, the BPG treatment subgroup or no BPG treatment subgroup vs. the blank group

from the blank group level $(P>0.05)]$ at $42 \mathrm{~d}$ postinfection.

\section{NLRP3 inflammasome expression in the organs of rabbits infected with $T$. pallidum}

Additionally, the dynamics of NLRP3, caspase-1, and IL$1 \beta$ mRNAs were monitored in five organs: the kidney, liver, spleen, lung, and testis. The results showed that NLRP3, caspase- 1 , and $I L-1 \beta$ mRNAs had different expression levels in the different organs of infected rabbits. The NLRP3 mRNA expression levels in the infection group showed a trend in elevation to decline in all five organs but was still higher than "normal" at the endpoint of the study (vs. the blank group, $P<0.05$ ) (Fig. 4a-e). Similar to the trend in NLRP3, caspase-1 mRNA showed an initial increase and then a decreasing trend later in four organs (kidney, liver, lung, and testis). The expression of caspase-1 mRNA in the kidney showed a "saddle pattern" of change over time post-infection, which was different from that in the other three organs (liver, lung, and testis) and remained higher than that in the blank group at the endpoint of the study $(P<0.05)$. However, caspase- 1 mRNA level in the spleen was not different among the BPG treatment subgroup, the no BPG treatment subgroup, and the blank group (Fig. 4f-j). Regarding the expression level of $I L-1 \beta$ mRNA, there was no difference in the testes among the BPG treatment subgroup, the no BPG treatment subgroup, and the blank group. However, $I L-1 \beta$ mRNA expression showed an earlier increase and later decrease in the kidney, liver, spleen, and lung and returned to normal at $21 \mathrm{~d}$ in the kidney and $42 \mathrm{~d}$ in the liver [vs. the blank group $(P>$ $0.05)]$. $I L-1 \beta$ mRNA was still expressed in the lung and spleen (vs. the blank group, $P<0.05$ ) at the endpoint of the study ( $42 \mathrm{~d}$ post-infection) (Fig. $4 \mathrm{k}-\mathrm{o}$ ).

\section{Discussions}

T. pallidum can provoke an intense innate immune response, which is generally believed to be the cause of tissue damage [14]. In a rabbit model, $T$. pallidum infection presents with the progression of macrophage activation and mononuclear cell infiltration at the sites of the experimental inoculation [15]. Immunohistochemistry and real time-PCR analysis of biopsy specimens obtained from primary and secondary syphilis lesions demonstrate that syphilitic skin lesions are also composed of macrophages and lymphocytes that express mRNAs for $I L-1 \beta$, Interferon- $\gamma$ and $I L-12$ in experimentally infected rabbit tissues [16] and human primary syphilitic lesions [17]. Results from prior studies have confirmed that innate immune cells, such as macrophages, can express pattern recognition receptors and sense microbes by recognizing the pathogen-associated molecular patterns of pathogens [18]; then various members of the NLR family in the cytoplasm are activated, resulting in the assembly of an NLR and the activation of caspase-1, leading to IL- $1 \beta$ production [4]. NLRP3 inflammasome activation/IL-1 $\beta$ release results in hepatocyte pyroptosis, liver inflammation, and fibrosis in mice [19]. In the present study, we found that NLRP3 inflammasome activation and IL-1 $\beta$ secretion were exhibited in T. pallidum-infected rabbits at the early phase and showed a trend in elevation to decline. The trend was similar to the changes in the lesions of the infected rabbits, which showed evidence of a link between NLRP3 inflammasome activation and inflammatory injury caused by the T. pallidum infection. The activation of the NLRP3 inflammasome is closely related to disease development.

Penicillin has been recommended as the mainstay of treatment for all types of syphilis since this drug was first used for this indication in 1943 [20]. In this study, we also investigated the effect of penicillin treatment on the expression of the NLRP3 inflammasome during the development of tissue inflammation due to syphilis. We found that regardless of whether the infected rabbits received BPG treatment, the expression levels of NLRP3, caspase- 1 , and $I L-1 \beta$ in cutaneous lesions all showed an identical trend in elevation to decline, similar to the 


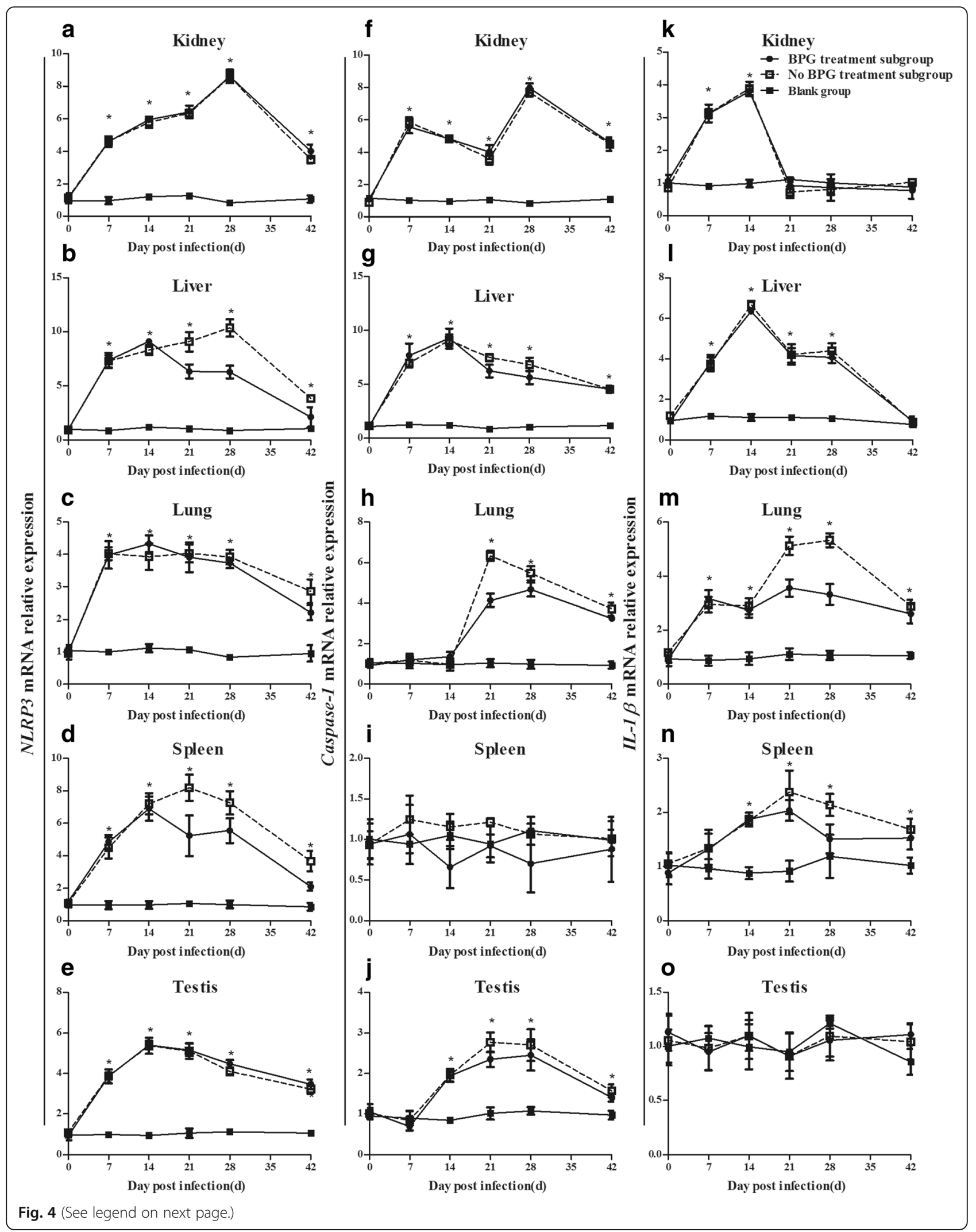


(See figure on previous page.)

Fig. 4 Dynamics of NLRP3, caspase-1, and IL-1 $\beta$ mRNA expression in organs of rabbits infected with T. pallidum. a-e Dynamics of NLRP3 mRNA expression in the kidney $(\mathbf{a})$, liver $(\mathbf{b})$, lung $(\mathbf{c})$, spleen $(\mathbf{d})$ and testis $(\mathbf{e})$. $\mathbf{f}-\mathbf{j}$ Dynamics of caspase-1 mRNA expression in the kidney $(\mathbf{f})$, liver $(\mathbf{g})$,

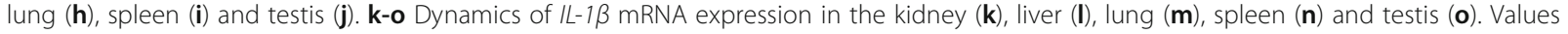
represent the mean \pm SD of triplicate experiments. A one-way analysis of variance was employed to examine the differences in groups, and Dunnett's post-comparison test was used to conduct multiple comparisons. ${ }^{*} P<0.05$, the BPG treatment subgroup or no BPG treatment subgroup vs. the blank group

trend found in the cutaneous lesions, and the expression of NLRP3, caspase- 1 , and $I L-1 \beta$ mRNAs in lesions eventually returned to "normal" levels in both the BPG treatment and no BPG treatment subgroups, but the time point of reduction was slightly different. The cutaneous lesions disappeared at an earlier time point (at $28 \mathrm{~d}$ ) in the BPG treatment subgroup than in the no BPG treatment subgroup (at $42 \mathrm{~d}$ ). In addition, NLRP3 mRNA expression was suppressed at an earlier time point in the BPG treatment subgroup (18 d) than in the no BPG treatment subgroup (21 d). BPG therapy imperceptibly adjusted syphilitic inflammation.

T. pallidum disseminates systemically and induces inflammation in diverse tissues and organs [21]. Innate immune cells, such as macrophages in tissues and organs not only mediate bacterial clearance but also lead to tissue damage and clinical symptoms [22]. In this study, we detected NLRP3 inflammasome activation in five organs, the kidney, liver, lung, spleen and testis, further confirming that T. pallidum induced systemic inflammatory during infection. We also found that $I L-1 \beta$ was expressed in the kidney, liver, lung and spleen tissue but was not detectable in the testes of the infected rabbits. One possible explanation is that there may be some difference in the number of IL-1 $\beta$-producing cells (such as macrophages) or in the cellular function cytokine production in response to T. pallidum stimulation among different organs, The other possible reason is that the testis represents a distinct immunoprivileged site where invading pathogens can be tolerated without evoking detrimental immune responses [23]. In addition, we found that NLRP3 was differently expressed in different organs and was also recovered at different times, further confirming the existence of different immune response profiles to T. pallidum in different organs. Additionally, only three animals were harvested for experimental analysis; thus, the possibility of individual differences in the immune response of animals may result in the nonregularity. Further study requires more animals to eliminate individual differences.

In this study, we demonstrated that T. pallidum-induced inflammasome activation was positively correlated with changes in the skin lesions of rabbits. Further studies are required to understand the mechanisms of NLRP3 inflammasome regulation by IL-1 $\beta$ in $T$. pallidum infection. Also, T. pallidum multiplicity may correlate with the different disease outcome [1, 24], the immune response to different T. pallidum strains would deserve our future study. In addition, we only monitored the changes at $42 \mathrm{~d}$ post-infection. Therefore, further studies are required to determine changes in the NLRP3 inflammasome in rabbits with relapse in the no BPG treatment subgroup.

\section{Conclusions}

In the present study, we established a clear link between NLRP3 inflammasome activation and the development of tissue inflammation in rabbits infected with T. pallidum; NLRP3 inflammasome activation was similar to the process of self-limited disease. We also found that BPG therapy imperceptibly altered the syphilitic inflammation, but the underlying mechanism remains unclear.

\section{Abbreviations}

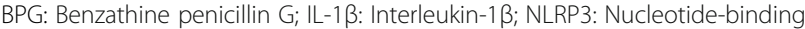
leucine-rich receptor protein 3

\section{Acknowledgements}

We acknowledge all the colleagues in Institute of Infectious Disease, Medical College of Xiamen University, for their assistance with sample collection, as well as their support in this project.

\section{Funding}

This work was supported by the National Natural Science Foundation [grant numbers 81772260, 81771312, 81672094, 81471967, 81471231, 81401749, $81301501,81201360,81271335,81101324,81171625]$, the Key Project of Cultivating Young Talent in Fujian Province's Health System [grant numbers 2013-ZQN-ZD-35 and 2014-ZQN-ZD-34], the National Science Foundation for Distinguished Young Scholars of Fujian [grant number 2014D001], the Youth Foundation Project of Fujian Provincial Health Department [grant number 2017-2-105, 2017-2-113, 2014-2-68], the Medical Innovation Project of Fujian Health Development Planning Commission[grant numbers 2014-CXB-40, 2012-CXB-33], the major special projects of serious illness in Xiamen [grant number 3502Z20159016, 3502Z20179045,] and the Natural Science Foundation of Fujian Province [grant number 2016 J01628, 2018D0014], The funders played no role in the study design, data collection, or analyses, the decision to publish, or manuscript preparation.

\section{Availability of data and materials}

The datasets generated during the current study are available from the corresponding author on reasonable request.

\section{Authors' contributions}

$Y L, L L L$ and TCY conceived and designed the study. $L R L, Y X$, and $W L$ analyzed the data and drafted the manuscript. YYC, XZZ, ZXG, and KG collected and organized the data. MLT, HLZ, SLL, HLL, WDL, XML keeped rabbits and collected samples. LRL, TCY, LLL, MLT, XML, YYC, YX and HLZ obtained the funding and revised the manuscript critically for important intellectual content. All authors read and approved the final manuscript. 


\section{Ethics approval}

This study was approved by the animal experimental ethics committee of the Medical College of Xiamen University.

\section{Consent for publication}

Not applicable.

\section{Competing interests}

The authors declare that they have no competing interests.

\section{Publisher's Note}

Springer Nature remains neutral with regard to jurisdictional claims in published maps and institutional affiliations.

\section{Author details}

'Zhongshan Hospital, Medical College of Xiamen University, Xiamen, Fujian Province, China. ${ }^{2}$ Institute of Infectious Disease, Medical College of Xiamen University, Xiamen, Fujian Province, China. ${ }^{3}$ Xiamen Hospital of Traditional Chinese Medicine, Xiamen, Fujian Province, China. ${ }^{4}$ Xiamen Fifth Hospital, Xiamen, Fujian Province, China. ${ }^{5}$ Xiamen Huli District Maternity and Child Care Hospital, Xiamen, Fujian Province, China.

\section{Received: 24 October 2017 Accepted: 13 February 2018}

Published online: 01 March 2018

\section{References}

1. Tong ML, Zhao Q, Liu LL, Zhu XZ, Gao K, Zhang HL, Lin LR, Niu JJ, Ji ZL, Yang TC. Whole genome sequence of the Treponema pallidum subsp. pallidum strain Amoy: An Asian isolate highly similar to SS14. Plos One. 2017;12(8):e0182768.

2. Salazar JC, Hazlett KR, Radolf JD. The immune response to infection with Treponema pallidum, the stealth pathogen. Microbes \& Infection. 2002;4(11):1133-40.

3. Weissleder R, Nahrendorf M, Pittet MJ. Imaging macrophages with nanoparticles. Nat Mater. 2014;13(2):125-38.

4. Leemans JC, Cassel SL, Sutterwala FS. Sensing damage by the NLRP3 inflammasome. Immunol Rev. 2011:243(1):152-62.

5. Gross O, Thomas CJ, Guarda G, Tschopp J. The inflammasome: an integrated view. Immunol Rev. 2011;243(1):136-51.

6. Wang Y, Wang GZ, Rabinovitch PS, Tabas I. Macrophage mitochondrial oxidative stress promotes atherosclerosis and nuclear factor-kappaBmediated inflammation in macrophages. Circ Res. 2014;114(3):421-33.

7. Zhang F, Wang L, Wang JJ, Luo PF, Wang XT, Xia ZF. The caspase-1 inhibitor AC-YVAD-CMK attenuates acute gastric injury in mice: involvement of silencing NLRP3 inflammasome activities. Sci Rep. 2016;6:24166.

8. Geldhoff M, Mook-Kanamori BB, Brouwer MC, Troost D, Leemans JC, Flavell RA, Van der Ende A, Van der Poll T, Van de Beek D. Inflammasome activation mediates inflammation and outcome in humans and mice with pneumococcal meningitis. BMC Infect Dis. 2013;13:358.

9. Perez-Figueroa E, Torres J, Sanchez-Zauco N, Contreras-Ramos A, AlvarezArellano L, Maldonado-Bernal C. Activation of NLRP3 inflammasome in human neutrophils by helicobacter pylori infection. Innate Immun. 2016;22(2):103-12.

10. Wang XC, Gong PT, Zhang X, Wang JL, Tai LX, Wang X, Wei ZK, Yang YJ, Yang ZT, Li JH, et al. NLRP3 inflammasome activation in murine macrophages caused by Neospora caninum infection. Parasit Vectors. 2017; 10(266):1-13. https://rd.springer.com/content/pdf/10.1186\%2Fs13071-0172197-2.pdf.

11. Wei M, Wang L, Wu T, Xi J, Han Y, Yang X, Zhang D, Fang Q, Tang B. NLRP3 activation was regulated by DNA methylation modification during mycobacterium tuberculosis infection. Biomed Res Int. 2016;2016:4323281.

12. Tong ML, Zhang HL, Zhu XZ, Fan JY, Gao K, Lin LR, Liu LL, Li SL, Lin HL, Lin ZF. Re-evaluating the sensitivity of the rabbit infectivity test for Treponema pallidum in modern era. Clin Chim Acta. 2017;464:136-41.

13. Zhang S, Liang $X$, Zheng X, Huang H, Chen X, Wu K, Wang B, Ma S. Glo genetic amplification as a potential therapeutic target in hepatocellular carcinoma. International Journal of Clinical \& Experimental Pathology. 2014;7(5):2079-90.

14. Frunza-Stefan S, Acharya G, Kazlouskaya V, Vukasinov P, Chiou Y, Thet Z. Immune reconstitution inflammatory syndrome associated with secondary syphilis. Int J STD AIDS 2017;28(3):302-305. http://journals.sagepub.com/doi/
abs/10.1177/0956462416664469?url_ver=Z39.88-2003\&rfr_id=ori:rid:crossref. org\&rfr_dat=cr_pub\%3dpubmed.

15. Sell S, Gamboa D, Bakerzander SA, Lukehart SA, Miller JN. Host response to Treponema pallidum in intradermally-infected rabbits: evidence for persistence of infection at local and distant sites. J Invest Dermatol. 1980;75(6):470-5.

16. Steinbach EC, Plevy SE. The role of macrophages and dendritic cells in the initiation of inflammation in IBD. Inflamm Bowel Dis. 2014;20(1):166-75.

17. Seider K, Gerwien F, Kasper L, Allert S, Brunke S, Jablonowski N, Schwarzmuller T, Barz D, Rupp S, Kuchler K, et al. Immune evasion, stress resistance, and efficient nutrient acquisition are crucial for intracellular survival of Candida Glabrata within macrophages. Eukaryot Cell. 2014;13(1):170-83.

18. Kaku Y, Imaoka H, Morimatsu Y, Komohara Y, Ohnishi K, Oda H, Takenaka S, Matsuoka M, Kawayama T, Takeya M, et al. Overexpression of CD163, CD204 and CD206 on alveolar macrophages in the lungs of patients with severe chronic obstructive pulmonary disease. PLoS One. 2014;9(1):e87400.

19. Wree A, Eguchi A, McGeough MD, Pena CA, Johnson CD, Canbay A, Hoffman HM, Feldstein AE. NLRP3 inflammasome activation results in hepatocyte pyroptosis, liver inflammation, and fibrosis in mice. Hepatology. 2014:59(3):898-910.

20. Mantovani A. The faces of macrophage activation. Eur J Clin Investig. 2013:43:10.

21. Peeling RW, Hook EW 3rd. The pathogenesis of syphilis: the great mimicker, revisited. J Pathol. 2006;208(2):224-32.

22. Schroder K, Zhou RB, Tschopp J. The NLRP3 Inflammasome: a sensor for metabolic danger? Science. 2010:327(5963):296-300.

23. Zhao S, Zhu W, Xue S, Han D. Testicular defense systems: immune privilege and innate immunity. Cell Mol Immunol. 2014;11(5):428.

24. Marra C, Sahi S, Tantalo L, Godornes C, Reid T, Behets F, Rompalo A, Klausner JD, Yin Y, Mulcahy F, et al. Enhanced molecular typing of treponema pallidum: geographical distribution of strain types and association with neurosyphilis. J Infect Dis. 2010;202(9):1380-8.

\section{Submit your next manuscript to BioMed Central and we will help you at every step:}

- We accept pre-submission inquiries

- Our selector tool helps you to find the most relevant journal

- We provide round the clock customer support

- Convenient online submission

- Thorough peer review

- Inclusion in PubMed and all major indexing services

- Maximum visibility for your research

Submit your manuscript at www.biomedcentral.com/submit
) Biomed Central 